\title{
LA REPARACIÓN INTEGRAL COMO PRINCIPIO PREVALENTE EN LA RESPONSABILIDAD DEL ESTADO -UNA VISIÓN A PARTIR DE LA JURISPRUDENCIA DE LA CORTE CONSTITUCIONAL Y DEL CONSEJO DE ESTADO COLOMBIANO- *
}

Comprenhensive reparation as a prevailing principle in the responsability of the state $-A$ perspective based on the Constitutional Court and the Colombian Council of State case-law-

Débora Guerra Moreno**

Liliana Damaris Pabón Giraldo***

Diana María Ramírez Carvajal****

Recepción: 04/01/2019. Aceptación: 07/12/2019

DOI: http://dx.doi.org/10.21017/Rev.Repub.2020.v28.a77

* Artículo de investigación producto del proyecto de tesis doctoral de Débora Guerra denominado: "Modelo de reparación integral para Colombia- Justicia restaurativa con vocación transformadora, un aporte atendiendo a las directrices aplicadas por los Tribunales internacionales (Corte Interamericana de Derechos Humanos y Tribunal Europeo de Derechos Humanos", desarrollado en el programa de Doctorado en Derecho Procesal Contemporáneo de la Universidad de Medellín, bajo la dirección de Liliana Damaris Pabón Giraldo y Diana María Ramírez Carvajal.

** Doctora en Administración, Hacienda y Justicia, de la Universidad de Salamanca, Magíster en Responsabilidad contractual y extracontractual civil y del Estado, Universidad Externado de Colombia, profesora investigadora de la Universidad Libre Seccional Cúcuta, colíder del Grupo de Investigación en Derecho Público. debora.guerra@ unilibre.edu.co

*** Abogada, Universidad de Medellín. Magíster en Derecho Procesal Universidad Nacional de Rosario. Magister en Derecho Procesal, Universidad de Medellín. Doctora en Derecho, Universidad Nacional de Rosario. Docente investigadora de la Facultad de Derecho de la Universidad de Medellín. Integrante y líder del Grupo de Investigaciones en Derecho Procesal de la Universidad de Medellín. Directora de la Maestría en Derecho Procesal extensiones. ldpabon@udem.edu.co

**** Profesora e investigadora, abogada y Magíster en Derecho Procesal de la Universidad de Medellín. Doctora en Derecho de la Universidad Externado de Colombia. Coodinadora de la red Interinstitucional para el estudio del derecho y la justicia. Actualmente es la decana de posgrados de la Universidad Católina de Oriente, adscrita al grupo de investigaciones jurídicas de la facultad de derecho. Radiana2113@gmail.com - posgrados@ uco.edu.co. 


\section{RESUMEN}

Este artículo aborda la reparación integral como derecho fundamental y principio orientador en la responsabilidad civil y del Estado, a fin de que sea tomado en cuenta de forma prevalente a la hora de valorar los daños materiales e inmateriales sufridos por las personas. Frente al tema, son múltiples las discusiones planteadas desde el punto de vista normativo, doctrinal e incluso jurisprudencial no solo en el ámbito interno sino en el ámbito internacional, por la ponderación que debe hacerse frente al mismo. No obstante, su evolución ha sido notable y con base a estándares internacionales, debe el juez aplicarlo de cara a lineamientos de protección de derechos humanos y de derecho internacional humanitario. Para su desarrollo, se acudió al análisis, evolución, contenido y alcance que ha tenido la reparación en los diversos instrumentos internacionales de los derechos humanos, para luego centrar el estudio en los criterios emitidos por la Corte Constitucional y el Consejo de Estado colombianos a partir de 1991, compaginando lo anterior con lo previsto por la doctrina. De allí que finalmente se plantee la configuración de la prevalencia de la reparación integral en la jurisprudencia colombiana, de cara al bloque de constitucionalidad y convencionalidad, y en búsqueda de una verdadera justicia restaurativa y transformadora.

Palabras clave: Reparación integral, responsabilidad civil, responsabilidad estatal, daño, víctima, derechos humanos, justicia restaurativa, justicia transformadora.

\section{ABSTRACT}

This paper addresses comprehensive reparation as a fundamental right and guiding principle in civil and State liability so that it is taken into account in a prevalent manner when assessing material and immaterial damages suffered by people. Due to the need to weigh such principle, there are many discussions raised from a normative, doctrinal, and - even- jurisprudential point of view, not only in the domestic sphere but also in the international sphere. However, its evolution has been remarkable and, currently, judges must apply it based on grounds of protection of human rights and international humanitarian law. For this research, the development, the analysis, the content, and the scope of the reparation principle was studied in the various international human rights instruments. Afterward, the research focuses on the criteria used by the Constitutional Court and the Council of State from 1991 onwards; along with the relevant doctrine on this subject. Lastly, the paper argues that the comprehensive reparation principle has consolidated as a prevalent principle within Colombian case-law which faces interesting interaction with the block of constitutionality and conventionality in the search of true restorative and transformative justice. 
Key words: Comprehensive reparation, civil liability, state responsability, harm, victim, human rights, restorative justice, transformative justice.

\section{INTRODUCCIÓN}

Los esfuerzos por asegurar la reparación de las víctimas realizados por la Organización de las Naciones Unidas desde la Declaración Universal de los Derechos Humanos proclamada por la Asamblea General el 10 de diciembre de 1948 y los demás convenios y tratados internacionales en materia de Derechos Humanos, son orientados bajo la directriz de que todos los pueblos y naciones garanticen y aseguren a la población, sin importar su condición social, económica, de sexo, raza, culto o inclinación sexual, ser tratada de manera igualitaria (ONU, 1948). Las Naciones Unidas han asegurado así, el establecimiento de los principios y directrices básicos sobre el derecho de las víctimas de violaciones manifiestas de las normas internacionales de derechos humanos y de graves violaciones del derecho internacional humanitario para interponer recursos y obtener su reparación. Como consecuencia, los principios y directrices aprobados por la Asamblea General de la ONU en el 2005 mediante Resolución 60/147, imponen a los Estados, entre otras, la obligación de garantizar, respetar y aplicar las normas internacionales en materia de protección de los derechos humanos y de derecho internacional humanitario en favor de las víctimas, para asegurar su derecho a interponer recursos y garantizar su derecho a ser reparadas de manera plena, adecuada, efectiva y célere. Estas directrices han sido aplicadas por la Corte Interamericana de Derechos Humanos para resolver casos de graves violaciones de los derechos humanos. Así su incidencia se ha reflejado en el ámbito nacional.

En Colombia, desde 1991, bajo la estructura de Estado Constitucional y Social de Derecho, se evidencia una generación de derechos que revelan la doble dimensión del hombre, como ser social e individual, se destacan algunos como: el derecho a una vida digna, a la autodeterminación, a un ambiente sano, entre otros; y el derecho a la reparación integral cuando se es víctima de la vulneración de los derechos humanos o de los derechos fundamentales. Por tal motivo, es importante indagar sobre el alcance del principio de reparación integral sobre de los daños causados por el Estado.

Por lo anterior, este artículo se divide en 4 partes: (i) se comienza con una aproximación al principio de reparación integral, su evolución, contenido y alcance en la responsabilidad civil, efectuando un acercamiento a su regulación en el bloque de constitucionalidad; (ii) luego se analiza la reparación integral como derecho fundamental y principio constitucional en la jurisprudencia de la Corte Constitucional en Colombia; (iii) a renglón seguido se analiza igual- 
mente la reparación integral como principio en la jurisprudencia del Consejo de Estado; y (iv) finalmente se hace referencia al daño inmaterial, a su evolución y sus diversas formas, que deben ser tenidas en cuenta a la hora de realizar la reparación integral, atendiendo a estándares internacionales.

\section{PROBLEMA DE INVESTIGACIÓN}

¿Cómo se configura la prevalencia del principio de reparación integral en la jurisprudencia de la Corte Constitucional y el Consejo de Estado en Colombia a partir del contenido y alcance que estas le han dado al deber de reparar en los procesos de responsabilidad del Estado?

\section{ESTRATEGIA METODOLÓGICA}

Para responder a la pregunta de investigacion formulada, se empleó un enfoque cualitativo y un tipo de estudio teórico, jurídico y analítico. Para ello se realiza un análisis de la evolución, el contenido y el alcance de la reparación desde su génesis en los diversos instrumentos del derecho internacional de los derechos humanos. Se ha centrado en el estudio de los criterios jurídicos emitidos por la Corte Constitucional y por el Consejo de Estado colombianos en su jurisprudencia, después de la Constitución de 1991. Se acudió a las diversas discusiones que frente a la reparación integral se han dado en la doctrina y a la posición que como derecho fundamental y principio han asumido la Corte Constitucional y el Consejo de Estado colombianos; para culminar con la prevalencia que este principio tiene a la hora de repararse tanto el daño material como las diversas formas del daño inmaterial, siempre siguiendo los estándares internacionales.

\section{El principio de reparación integral, su concepto en la responsabilidad civil y ubicación en el bloque de constitucionalidad}

Para determinar la reparación integral como un principio, es necesario apropiar una institución jurídica que dé origen al deber de reparar. Al respecto una de las máximas de Ulpiano decía: "Los preceptos del derecho son: vivir honestamente, no dañar a nadie y dar a cada uno lo que es suyo" (Iuris praecepta sunt haec: honeste vivere, alterum non laedere, suum cuique tribuere, D.1.1.10.1)" (Trad. Idelfonso, 1889). Precepto que se ubica en el escenario de la Responsabilidad Civil, vital dentro de un ordenamiento jurídico. Y así desde épocas remotas, paso a paso se fueron dando figuras tales como la proporcionalidad para establecer el resarcimiento del daño sufrido (Ley del Talión), la composición voluntaria que incorporó las sanciones pecuniarias en el Código de Hammurabi, 
para dar origen a la composición legal como pena privada contenida en la Ley de las XII Tablas, que evolucionaron y sirvieron a su vez de base para establecer en el Derecho Romano la Lex Aquilia (Trad. Idelfonso, 1889), en la que se instituyeron las bases normativas de lo que hoy se conoce como responsabilidad civil extracontractual. Concepto que está integrado a otras nociones relacionadas con el ser y el deber ser, que exige un comportamiento adecuado, ético, honesto, diligente y enmarcado en la norma.

A su vez, desde las bases normativas establecidas en el derecho romano y específicamente en la compilación de Justiniano, se construyó la teoría de la responsabilidad civil y se introdujo como novedad en el Código de Napoleón el principio general de responsabilidad civil extracontractual por culpa, dejando atrás la función sancionatoria que contenía la Ley Aquiliana y dando paso a la acción resarcitoria como finalidad de esta institución jurídica en el artículo 1382 del Código Civil Francés (Código Civil, 1804). Se puede observar que el vocablo responsabilidad refleja una obligación, según Kelsen (2010) una obligación jurídica y según Hart (2016) podría representar varios significados o símbolo de diferentes contenidos: como capacidad, factor causal, deber y obligación derivada de un cargo o rol social y como sancionabilidad. En este orden de ideas, se establece el concepto universal de "responsabilidad civil", entendida como: la obligación de reparar el daño causado, pero no cualquier daño, sino solo aquel que recae sobre un bien, interés o derecho jurídicamente protegido (Guerra, 2015, p. 162). Esta definición permite integrar tanto la concepción de Kelsen, como la de Hart.

Como corolario de lo anterior, se debe comprender que la finalidad de la responsabilidad civil es la reparación de los perjuicios que sufre una persona como consecuencia de un daño que se ha causado a sus intereses o bienes protegidos por el derecho, bien sean individuales o colectivos. Y para determinar qué se debe reparar, es necesario conceptualizar el daño. Según Henao, "el daño es toda afrenta a los intereses lícitos de una persona, trátese de derechos pecuniarios o de no pecuniarios, de derechos individuales o colectivos, que se presenta como lesión definitiva de un derecho o como alteración de su goce pacífico y que, gracias a la posibilidad de accionar judicialmente, es objeto de reparación si los otros requisitos de la responsabilidad civil -imputación y fundamento del deber de reparar- se encuentran reunidos" (Henao, 2007, p. 133). Por su parte, Tamayo basándose en la teoría del derecho subjetivo de Von lhering, expresa que la lesión a los bienes no constituye la esencia del daño civil, ya que lo que la ley protege es el interés que los particulares tienen en esos beneficios patrimoniales o morales. En consecuencia, se define como daño en sentido jurídico el menoscabo de un interés jurídicamente protegido (Tamayo, 1983, p. 38). A su vez, para De Cupis, el daño es la aminoración de una situación favorable (1970). Y para Escobar Gil significa "todo detrimento, menoscabo o perjuicio que, a 
consecuencia de un acontecimiento determinado, experimenta una persona en sus bienes espirituales, corporales o patrimoniales, sin importar que la causa sea un hecho humano inferido por la propia víctima o por un tercero o que la causa sea un hecho de la naturaleza" (Escobar, 1989, p. 165). Así las cosas, se puede concebir el daño como toda lesión, disminución, aminoración o afectación que recae sobre un bien jurídicamente tutelado.

Estas definiciones generales sobre la responsabilidad civil y sobre el daño, construidas a partir de la legislación civil ${ }^{1}$, se constituyeron desde los inicios del siglo XX en el fundamento para determinar la responsabilidad del Estado cuando éste, a través de la actuación de sus agentes, lesiona intereses o derechos de los ciudadanos. Es a partir de 1991 que, en la Constitución Política de Colombia, se introduce expresamente la responsabilidad a cargo del Estado en la siguiente forma: “Artículo 90. El Estado responderá patrimonialmente por los daños antijurídicos que le sean imputables, causados por la acción o la omisión de las autoridades públicas" (Asamblea Nacional Constituyente, 1991). En consecuencia, para que el Estado Colombiano sea obligado a reparar los perjuicios que se causen a un ciudadano o a un colectivo, debe probarse que ha causado un daño antijurídico y que este resultado dañino le es imputable debido a la falla de sus acciones, omisiones u operaciones a través de las cuales desarrolla los fines esenciales del Estado ${ }^{2}$, asegurando la reparación integral a quien lo sufrió. En este sentido, deben ser reparados tanto los daños que recaigan sobre bienes materiales como los que afecten los bienes inmateriales.

Conforme a lo anterior, en Colombia se han establecido diferentes tipos de daños o perjuicios. Los materiales desarrollados en el Código Civil, en sus artículos 1613 y 1614, que se refieren al daño emergente y al lucro cesante. Los inmateriales han sido desarrollados vía jurisprudencia del Consejo de Estado, de la Corte Suprema de Justicia y de la Corte Constitucional, órganos que han dado nacimiento a diferentes categorías de daño inmaterial, como lo son: el daño moral, el daño a la salud y el daño a bienes constitucional o convencionalmente protegidos, manteniendo en algunos casos el daño a la vida de relación o la alteración a las condiciones de existencia. Y una vez se haya probado dentro del proceso la existencia del daño y el fundamento del mismo, la conexión entre el primero y el segundo, permite construir un nexo causal fáctico, y es ahí que surge el deber de reparar.

1 Ver Código civil colombiano - artículos2341 y ss (Ley 84, 1873).

2 Así por ejemplo, para que se declare la responsabilidad del Estado por "acciones u omisiones de los que ejercen la función jurisdiccional, se debe probar: la existencia del daño, la existencia de un acto o hecho de la rama judicial y la relación causal entre uno y otro" (Guerra y Quintero, 2015, p. 147). 
La existencia del daño se prueba ante el juez a través de un conjunto de argumentos probabilísticos, donde se articulan múltiples fuentes de prueba (Ramírez, 2019). En primer lugar, debe evidenciar que se tiene la titularidad o disponibilidad del bien o derecho que se ha vulnerado, bien sea porque la titularidad se haya adquirido conforme a las diferentes maneras establecidas en la ley o porque en razón del principio de confianza legítima así se pueda considerar, y, segundo allegando todos los elementos que le permitan al juez revisar los antecedentes que necesariamente debieron presentarse para que el resultado "daño" fuera el esperado conforme al curso normal de los acontecimientos, o sea proporcionando al juez, suficiente material para que pueda establecer diferentes análisis de las situaciones fácticas probables para llegar a la certeza de que el bien jurídicamente tutelado ha sido lesionado como consecuencia de esos supuestos fácticos.

De allí que se estableció por la doctrina (De Cupis, 1970) y la jurisprudencia de la Corte Suprema de Justicia y del Consejo de Estado que el daño debe ser cierto, real, o incluso, se puede proyectar hacia el futuro, caso en el cual, ha señalado la Corte Suprema de Justicia que el elemento cierto no puede tomarse de manera estricta sino "en un sentido relativo, por lo que, respecto de su producción futura no podrá exigirse una certidumbre absoluta". En este último caso, ha expresado la Corte Suprema de Justicia que la certeza se debe establecer con base en la proyección razonable y objetiva que se haga de hechos presentes o pasados susceptibles de constatación, en el supuesto de que el daño aún no sea evidente o no se haya consolidado, luego se remite a una cuestión de hecho sujeta a la razonable valoración que hace el juzgador del marco concreto de circunstancias fácticas según las normas jurídicas, las reglas de la experiencia, la lógica y el sentido común. Cuando del daño futuro se trata, ha sido explícita "en que no es posible aseverar, con seguridad absoluta, cómo habrían transcurrido los acontecimientos sin la ocurrencia del hecho", acudiendo al propósito de determinar "un mínimo de razonable certidumbre", a "juicios de probabilidad objetiva" y "a un prudente sentido restrictivo cuando en sede litigiosa, se trata de admitir la existencia material del daño" (Sentencia SC1994-26630, 2013) ${ }^{3}$.

Por su parte, el Consejo de Estado ha señalado la necesidad de certeza para que un daño pueda ser reparado, indicando que "debe ser cierto y, por ende, edificarse en situaciones reales, existentes al momento de ocurrencia del evento dañino, toda vez que el perjuicio eventual o hipotético, por no corresponder

3 Al respecto puede ser consultada también: (Corte Suprema de Justicia, Sentencia SC11575, 2015). 
a la prolongación real y directa del estado de cosas producido por el daño, no es susceptible de reparación" (Sentencia 13168, 2006) ${ }^{4}$.

Frente al tema, el profesor Henao (2007) refiere que la certeza del perjuicio no puede definirse en sí misma, puesto que es su prueba la que la determina. Menciona que la tradición doctrinaria en materia de responsabilidad civil plantea que el daño es cierto cuando se evidencia que hay lesión definitiva del derecho, sin embargo, adiciona una postura que hace referencia a contemplar la amenaza como un daño cierto que debe repararse. En este sentido expresa que el daño existe desde el momento en el cual se altera su goce pacífico, y aun antes de que se inicie la consumación de su lesión (Henao, 2015). Aún con esta postura, se debe establecer la diferencia entre perjuicio futuro o la amenaza con el perjuicio eventual e hipotético.

En consecuencia, para que el daño sea reparado debe existir certeza sobre su ocurrencia, bien porque ya se encuentre consolidado, consumado, realizado o porque aun no habiéndose consolidado, resulten serias las probabilidades de que se proyecte hacia el futuro, toda vez que, se tiene la certeza de la situación de daño que existe en el presente y que puede continuar realizándose en el futuro (Guerra 2015). Y una vez sea obtenida la conexión entre el hecho y el daño y se haya probado la existencia de este último, se podrán establecer los criterios para ordenar reparación integral, efectiva, adecuada y plena.

\subsection{Concepto de reparación- Hacia lo integral, restaurativo y transformador}

El verbo reparar guarda relación simétrica con los verbos indemnizar, resarcir, restablecer, componer, compensar y restituir. Esto puede generar confusión frente al concepto de "reparar". En ese sentido, se pretende en el campo de la responsabilidad civil asegurar un concepto omnicomprensivo que se configura en la finalidad y naturaleza de la misma, cual es, la reparación integral. Ésta se corresponde con el principio general de la responsabilidad civil, toda vez que consiste en lograr el restablecimiento de la persona que sufre el daño, es decir, asegurar que volverá a la situación anterior -statu quo- que tenía antes de que se produjera el hecho generador del daño.

La reparación en el derecho de daños ha evolucionado a partir de la política implementada mediante directrices por la Organización de las Naciones Unidas, desarrollada en el derecho internacional por la Corte Interamericana de Derechos Humanos, para asegurar la garantía y el respeto de los derechos

4 Posición que ha sido reiterada, entre otras, en las sentencias: (Consejo de Estado, Sentencia 31583, 2014; Sentencia 35930, 2014 y Sentencia 36149, 2014). 
humanos y del Derecho Internacional Humanitario por parte de los Estados. Esta política adquiere relevancia en el derecho contemporáneo, pues en ella ha incidido de forma trascendental las decisiones internacionales respecto a la reparación de daños a las víctimas de violación de derechos humanos y, como consecuencia de ello, en el derecho interno colombiano (Pabón, 2015).

$\mathrm{Al}$ respecto, la Corte Constitucional en un caso de desplazamiento forzado, desarrollando el artículo 90 de la Constitución Política y el artículo 2341 del Código Civil, establece el derecho a la reparación a través del cual se debe buscar que la persona quede indemne-como si el hecho no hubiere ocurrido, y señala:

Las autoridades competentes tienen la obligación y la responsabilidad de prestar asistencia a los desplazados internos que hayan regresado o se hayan reasentado en otra parte, para la recuperación, en la medida de lo posible, de las propiedades o posesiones que abandonaron o de las que fueron desposeídos cuando se desplazaron. Si esa recuperación es imposible, las autoridades competentes concederán a esas personas una indemnización adecuada u otra forma de reparación justa o les prestarán asistencia para que la obtengan (Sentencia T-327, 2001).

La alta Corporación, a través de varias sentencias sobre desplazamiento forzado ${ }^{5}$, ha reconocido a la reparación integral la condición de derecho fundamental (Sentencia T-085, 2005), y como principio constitucional; con esto busca consolidar las bases de la reparación de las víctimas, inicialmente a las víctimas de desplazamiento forzado. En la actualidad, esta naturaleza de la reparación se aplica, no solo respecto de la violación de derechos humanos ${ }^{6}$ (desplazamiento forzado, ejecuciones extrajudiciales, esclavitud, entre otros), sino también en el derecho ordinario, lo que propicia un análisis hermenéutico para la dignificación de las personas. Lo indicado, conllevó la incorporación en el derecho interno de los principios y directrices contenidos en la Resolución AR/ 60147 de 2005 emitida por la Organización de las Naciones Unidas ${ }^{7}$, como se evidencia en la Ley 975 de 2005 y en la Ley 1448 de 2011, aunque el principio de reparación integral ya se encontraba en la Ley 446 de 1998.

5 Las sentencias consultadas son: (Corte Constitucional, Sentencia SU-254, 2013; Sentencia C-820, 2012; Sentencia C-715, 2012; Sentencia T-159, 2011; Sentencia T-085, 2009; Sentencia T-821, 2007; Sentencia C-370, 2006; Sentencia C-228, 2002; Sentencia T-159, 2011; Sentencia T-076, 2011).

6 Respecto al derecho a la reparación de violaciones a los derechos humanos puede consultarse (Gómez, 2014).

7 Sobre los antecedentes de esta Resolución puede consultarse (Guerra, 2015). 
Por lo tanto, la reparación de daños en los casos mencionados consiste en retornar a la víctima de las violaciones de derechos humanos a las condiciones que tenía antes de que se produjera el daño; para ello es necesario revisar en cada caso las situaciones sociales, culturales y políticas que lo rodean, toda vez que las particularidades varían esta perspectiva. Específicamente en Colombia, cada día crece el número de víctimas, por diversas violaciones de bienes jurídicamente protegidos, como consecuencia de fenómenos sociales y de orden público, asociados de manera directa, a veces, al conflicto armado interno y otras con actores indirectos del conflicto ${ }^{8}$. Por ello ha sido una constante desde el 2007, que el Consejo de Estado con la finalidad de garantizar los derechos de las víctimas, haya ordenado la reparación integral en los casos de violación de derechos humanos y de derechos fundamentales, adoptando medidas para fortalecer en el país, la dignidad, la solidaridad, la equidad, la buena fe, la igualdad y el debido proceso, entre otros, en un escenario basado en justicia restaurativa.

Conforme a lo anterior, las altas Cortes colombianas han asumido que la violación de los derechos genera la necesidad del restablecimiento del equilibrio en la persona, en sus diferentes dimensiones objetiva y subjetiva, esto es, material, corporal, social y emocional. Por ello se impone retornar a la víctima al statu quo de la generación del daño, buscando compensarla en todas sus esferas tanto internas como externas.

Según lo expuesto, el principio de reparación integral impone reparar todo el daño, pero no más allá de la magnitud del daño (Mazeaud, Mazeaud, Tunc, Capitant, y Alcalá Zamora, 1997), es decir, reparar la totalidad de los daños, pero sin superar el límite de estos. En este sentido afirma Henao Pérez, citado por Sandoval Garrido que "si el daño se indemniza por encima del realmente causado, se produce un enriquecimiento sin justa causa a favor de la víctima, si el daño se indemniza por debajo del realmente causado, se genera un empobrecimiento sin justa causa para la víctima" (Sandoval, 2013, p. 241) ${ }^{9}$. Motivo por el cual la ponderación en el equilibrio del resarcimiento del daño es impor-

8 Las cifras de víctimas del conflicto armado interno en Colombia ascienden a 8.731.105 personas según reporte del Registro Único de Víctimas -RUV- (Unidad de Víctimas, 2019).

9 En este sentido, señalan los hermanos Mazeaud: “... la cuantía de los daños y perjuicios no debe ser superior ni inferior al perjuicio que sufra la víctima y del que responda el autor de la culpa. En algunos supuestos particulares, puede pertenecerle al legislador disminuir o aumentar el importe de la reparación. El juez no tiene el derecho de arrogarse, por su propia autoridad, semejante poder. El responsable debe ser condenado a la reparación de todo el daño y tan sólo a la del daño causado por su culpa" (Mazeaud, Mazeaud, Tunc, Capitant, y Alcalá Zamora y Castillo, 1997, p. 523). 
tante en Colombia, porque el derecho ha entendido que el objetivo ideal de la reparación es retornar a la víctima a la situación que gozaba antes de la ocurrencia del hecho antijurídico, es decir, retrotraer, en la mayor medida de lo posible, las consecuencias de la vulneración, para llevar a la víctima a la situación en la que estaría si los hechos violatorios no hubieren ocurrido (Guzmán, 2009).

Así pues, el principio de reparación integral implica para la responsabilidad civil, una obligación de restablecimiento tanto del daño material como inmaterial, que signifique para la víctima la recuperación total de las condiciones que tenía antes de sufrir el daño, y en caso de no ser posible, acercándola a esas condiciones de vida que tenía antes de que se produjera el hecho dañino. Así lo establece en Colombia el artículo 16 de la Ley 446 de 1998 que señala, que la valoración de los daños irrogados a las personas o bienes debe atender a los principios de reparación integral y de equidad, al igual que lo establece la Resolución AR60/147 de 2005 incorporada al derecho interno en la Ley 975 de $2005^{10}$ y en el artículo 25 de la Ley 1448 de $2011^{11}$.

En igual sentido se expresa Uprimny (2010), para quien las reparaciones en Colombia son abordadas desde una perspectiva estrictamente restitutiva, buscando en cierta medida borrar, hasta donde sea posible, los efectos de los atentados contra la dignidad humana. No obstante para volver a la víctima a su situación anterior, la reparación debe ser integral y proporcional al daño sufrido, por lo que, si la restitución total no es posible, debe recurrirse a mecanismos reparadores sustitutos y complementarios, como la compensación y las medidas de rehabilitación, satisfacción y garantías de no repetición.

De lo expuesto, se desprenden dos características esenciales del principio de reparación integral, el carácter restitutivo y la necesidad de que sea verdaderamente integral, pero además de esto, la reparación debe ser "adecuada,

10 “ARTÍCULO 8o. DERECHO A LA REPARACIÓN. El derecho de las víctimas a la reparación comprende las acciones que propendan por la restitución, indemnización, rehabilitación, satisfacción; y las garantías de no repetición de las conductas..." (Congreso de la República, Ley 975, 2005).

11 “ARTÍCULO 25. DERECHO A LA REPARACIÓN INTEGRAL. Las víctimas tienen derecho a ser reparadas de manera adecuada, diferenciada, transformadora y efectiva por el daño que han sufrido como consecuencia de las violaciones de que trata el artículo $3 o$ de la presente Ley. La reparación comprende las medidas de restitución, indemnización, rehabilitación, satisfacción y garantías de no repetición, en sus dimensiones individual, colectiva, material, moral y simbólica. Cada una de estas medidas será implementada a favor de la víctima dependiendo de la vulneración en sus derechos y las características del hecho victimizante..." (Congreso de la República, Ley 1448, 2011). 
diferenciadora, transformadora y efectiva" (Ley 1448, 2011), con lo que se incorpora la reparación integral contenida en la Resolución 60/147 de la ONU. El alcance de estos conceptos implica: i) que la reparación sea adecuada, que se identifique y corresponda a las condiciones que serán restablecidas, ii) que sea diferenciadora, conforme a las condiciones y características específicas de cada caso para el restablecimiento de la víctima en la búsqueda de igualdad material y la justicia para lograr la igualdad real entre las distintas tipologías de víctima, iii) que sea transformadora, para el mejoramiento de las condiciones que tenía la víctima aún antes de los hechos victimizantes con el fin de que regrese a mejores condiciones de las que se encontraba, con ello se logra que sea útil y que persista en el tiempo (Bernal, 2017) y iv) efectiva, cuando se logra el objetivo para el cual fue desarrollada, la materialización de la reparación.

Respecto a estas desigualdades, propias de muchos colombianos, Rodrigo Uprimy considera que en contextos de transición y en sociedades desiguales, el ideal de reparación integral de las víctimas de violaciones graves a los derechos humanos conduce a un dilema difícil en el que se debe comenzar por enfatizar las diferencias entre una política social y los programas de reparación establecidos por el Estado dentro de un escenario de conflicto armado, con el fin de preservar el derecho específico de las víctimas a la reparación. Uprimy propone la noción de reparación transformadora como una forma de puente o vínculo entre ambos tipos de políticas y como una estrategia para reducir las tensiones entre la justicia distributiva y la justicia correctiva en esos contextos (Uprimny y Guzmán, 2010).

Diferente posición expresa Henao, quien considera que no puede admitirse la reparación transformadora como una forma de reparación, al respecto expresa que se

altera por completo la lógica milenaria de la responsabilidad civil, y convierte al juez en un ilegítimo dispensador de políticas públicas que lleva a la ruptura del principio de igualdad de las víctimas y que, por lo demás, conduce a que las innumerables sentencias condenatorias sean de imposible cumplimiento. Podría así el juez estar tentado a manejar un "populismo jurídico" en donde determine el futuro económico del país, lo cual estimo no es conveniente para una democracia (Henao, 2015, p. 353).

Pero como bien lo señala Arturo Solarte (2009), la reparación integral no debe terminar siendo una simple sustitución "estática" de activos, sino que adicionalmente deberá compensarle los otros perjuicios que le hayan ocasionado. En este sentido se expresa la Ley 1448 de 2011 cuando considera que que se puedan establecer otras medidas que incorporen una transformación de las condiciones que seguramente se constituyeron en la causa del daño. 


\subsection{La reparación integral en el Bloque de Constitucionalidad}

Las diferentes formas de agresión a la dignidad de las personas, la devastación sufrida por las naciones después de las guerras de carácter mundial, los regímenes totalitaristas, dictatoriales, han generado innumerables situaciones de violaciones de los derechos, muchas de estas violaciones aún perduran en el tiempo sin haber sido sanadas, reparadas u olvidadas. En razón de esto, la Organización de las Naciones Unidas, guiada por la Declaración Universal de los Derechos Humanos (1948), ha desarrollado sendos estudios en procura del establecimiento de las obligaciones internacionales de los Estados miembro para proteger y garantizar los derechos de los individuos, bajo los principios de dignidad humana, de solidaridad y de equidad que deben ser los orientadores de la administración pública y de justicia cuando se pretende asegurar la efectividad de un Estado social de derecho.

El Estado Colombiano ha establecido en el artículo 93 de la Constitución Política, en cumplimiento de las obligaciones convencionales ${ }^{12}$, la prevalencia en el orden interno del reconocimiento de los derechos humanos conforme a los tratados y convenios internacionales. En ese orden de ideas, los tratados, declaraciones, pactos o convenciones mencionados integran el bloque de constitucionalidad, que obliga a las autoridades colombianas, no solo a desaplicar, sino incluso, a anular las normas internas que les sean contrarias (Brewer y Santofimio, 2013, p. 47), toda vez que se encuentran a la altura de las contenidas en la Constitución, por ende poseen igual rango de aplicación en el derecho interno por ser fuentes del derecho que representan los valores y principios de un Estado social.

En este sentido, la Corte Constitucional colombiana ha declarado que "dado el rango constitucional que les confiere la carta, las disposiciones que integran el bloque superior cumplen la cuádruple finalidad que les asigna Bobbio, a saber: i) servir de regla de interpretación respecto de la dudas que puedan suscitarse al momento de su aplicación; ii) integrar la normatividad cuando no exista norma directamente aplicable al caso; iii) orientar las funciones del operador jurídico, y iv) limitar la validez de las regulaciones subordinadas" (Sentencia C-067, 2003).

Para asegurar la protección y garantizar los derechos humanos y los derechos fundamentales y teniendo en cuenta el deber funcional derivado de la Con-

12 Tales como: (Organización de los Estados Americanos, 1969); (Declaración Universal de Derechos Humanos, 1948); (Convención para prevenir y sancionar la totura, 1985); (V Convenio de Ginebra, 1949); (Pacto Internacional de Derechos Civiles y Políticos, 1966); (Protocolo de San Salvador, 1988). 
vención Americana de los Derechos Humanos, Colombia incorporó en su artículo 90 constitucional (Asamblea Nacional Constituyente, 1991), la cláusula general de responsabilidad a cargo del Estado. Ello significó un cambio de paradigma en cuanto a la responsabilidad se refiere. Con esta norma constitucional se propicia un proceso de transformación del sistema jurídico y comienza la materialización efectiva de la reparación integral con finalidad orientadora de las decisiones judiciales en materia de valoración del daño. Así pues, se propicia la transición de un juez con facultades discrecionales de ponderación y proporcionalidad permitiendo el afianzamiento en Colombia de un Estado Social de Derecho, que por fuente de convencionalidad, respeta la dignidad humana, hace uso del ejercicio efectivo de los derechos humanos y propicia la materialización del derecho a obtener una compensación justa, por las consecuencias derivadas de situaciones constitutivas de daño ${ }^{13}$.

En consecuencia, la reparación integral hace parte del bloque de constitucionalidad en razón del artículo 9y del inciso segundo del artículo 93 de la Constitución Política de Colombia, de manera que su interpretación como derecho a la reparación y de las obligaciones que de él se derivan, debe ajustarse a lo dispuesto en los siguientes tratados de derechos humanos ratificados por el Estado colombiano:

1) Pacto Internacional de Derechos Civiles y Políticos, en los términos del artículo 9.5: "Toda persona que haya sido ilegalmente detenida o presa, tendrá el derecho efectivo a obtener reparación" (Subrayado fuera del texto) (ONU, 1966).

2) Convención Americana sobre Derechos Humanos, establece en su artículo $10^{\circ}$ el derecho que tiene toda persona a ser indemnizada "conforme a la ley en caso de haber sido condenada en sentencia firme por error judicial"; $y$ dispone, asimismo, "si ello fuera procedente, que se reparen las consecuencias de la medida o situación que ha configurado la vulneración de esos derechos y el pago de una justa indemnización a la parte lesionada" (Subrayado fuera del texto) (OEA, 1969).

3) Convención contra la tortura y otros tratos o penas crueles, inhumanos o degradantes, en su artículo 14 .1 señala la obligación de los Estados parte de velar porque las legislaciones internas "garanticen a quienes hayan sido

13 Una de las formas de reparación del daño que se contemplan en el marco del Estado Social de Derecho previsto desde la Constitución Política de 1991 es la condena en abstracto en sede de la acción constitucional de tutela, siendo esta una novedosa forma de reparación de daños. Al respecto puede verse: (Yáñez, 2016). 
víctimas de actos de tortura, el derecho a una indemnización justa que incluya medios que permitan su rehabilitación de la forma más completa posible" (Subrayado fuera del texto) (ONU, 1984).

4) La Convención sobre los Derechos del Niño, donde se impone en su artículo 39, la obligación a los Estados parte de adoptar todas las medidas que resulten apropiadas que "se promueva la recuperación tanto física como psicológica, así como la reintegración social de aquellos niños que han sido víctimas de "cualquier forma de abandono, explotación o abuso; tortura u otra forma de tratos o penas crueles, inhumanos o degradantes; o conflictos armados", todo esto en un ambiente que "fomente la salud, el respeto de sí mismo y la dignidad del niño" (Subrayado fuera del texto) (ONU, 1989).

5) Estatuto de la Corte Penal Internacional que en su artículo 75 en relación con la reparación a las víctimas señala que, esa Corporación "establecerá principios aplicables a la reparación, incluidas la restitución, la indemnización y la rehabilitación, que ha de otorgarse a las víctimas o a sus causahabientes" así mismo, indica en relación con las decisiones proferidas por ese tribunal, que "La Corte podrá dictar directamente una decisión contra el condenado en la que indique la reparación adecuada que ha de otorgarse a las víctimas, incluidas la restitución, la indemnización y la rehabilitación..." (Subrayado fuera del texto) (CPI, 1998).

6) El Protocolo Adicional a los Convenios de Ginebra relativo a la Protección de las Víctimas de los Conflictos Armados Internacionales (Protocolo I): Artículo 91. Responsabilidad. La Parte en conflicto que violare las disposiciones de los Convenios o del presente Protocolo estará obligada a indemnizar si hubiere lugar a ello. Será responsable de todos los actos cometidos por las personas que formen parte de sus fuerzas armadas (ONU, 1977).

7) Convención Interamericana para prevenir, sancionar y erradicar la violencia contra la mujer (OEA, 1994).

8) Convenio No. 169 de la OIT sobre los pueblos indígenas y tribales en países independientes (OIT, 1989).

9) La Convención de La Haya relativa a las leyes y costumbres de la guerra terrestre (Comité Internacional de la Cruz Roja, 1907).

10) Resolución 60/147 de las Organización de las Naciones Unidas, por medio de la cual se establecen los Principios y directrices básicos sobre el derecho de las víctimas de violaciones de las normas internacionales de Derechos 
Humanos y de violaciones graves del Derecho Internacional Humanitario a interponer recurso y obtener reparaciones (ONU, 2005).

Por lo expuesto en estas normas, la Corte Constitucional (Sentencia T-1319, 2001) ha señalado que la jurisprudencia y doctrina de las instancias internacionales de derechos humanos, constituyen pautas relevantes para interpretar el alcance de esos tratados y, por ende, de los propios derechos constitucionales. Por ello el bloque de constitucionalidad y el control de convencionalidad ${ }^{14}$, relativos al principio de reparación integral, está integrado por las normas contenidas en los tratados ya mencionados y por las interpretaciones que de estos han hecho y hagan el Comité de Derechos Humanos, la Comisión de Derechos Humanos, la Comisión Interamericana de Derechos Humanos y la Corte Interamericana de Derechos Humanos. En todo ello, cobran además relevancia las resoluciones proferidas por el Consejo de Seguridad de Naciones Unidas, pues según lo dispuesto en el artículo 25 de la Carta de las Naciones Unidas (ONU, 1945), las decisiones adoptadas por este organismo son obligatorias para los Estados miembros, por tanto, estos documentos deben tenerse como referentes útiles para precisar el contenido del derecho a la reparación integral y las correlativas obligaciones del Estado.

\section{La reparación integral como derecho fundamental y como principio cons- titucional en la jurisprudencia de la Corte Constitucional colombiana}

Tal como se indicó en el acápite anterior, la Corte Constitucional en el año 2001, dejó entrever por primera vez, sin que así lo mencione, la reparación integral como un derecho fundamental. En ella consideró que se debe asegurar y garantizar a las víctimas de violaciones de derechos humanos y del derecho internacional humanitario, conforme a los preceptos constitucionales y convencionales, el derecho a la justicia, lo que implica el derecho a obtener claridad sobre la ocurrencia de los hechos, a que la persona responsable sea investigada y sancionada. En esta sentencia igualmente consideró que se debe asegurar el derecho a la verdad, cuyo fin se establece en que las víctimas conozcan la verdad sobre los hechos y circunstancias en que se cometieron las violaciones, y en caso de fallecimiento o desaparición, acerca de la suerte que corrió la víctima. Por último, considera que a través del derecho a la reparación se debe asegurar que la persona víctima quede indemne -como si el hecho no hubiere ocurrido (Sentencia T-327, 2001).

14 Sobre el control de convencionalidad puede verse: (Sánchez, 2015); (Cubides, Chacón y Martínez, 2015). 
Posteriormente, en la sentencia T-821 de 2007, la Corte Constitucional consideró de forma expresa que el derecho a la reparación integral del daño causado a víctimas de violaciones masivas y sistemáticas de derechos humanos es un derecho fundamental (Sentencia T-821, 2007). Para ello fundamentó su decisión en el artículo 17 del Protocolo Adicional de los Convenios de Ginebra de 1949 y los Principios Rectores de los Desplazamientos Internos (los llamados principios Deng) (ONU, 1998), resaltando los Principios 21, 28 y 29, así como los Principios sobre la restitución de las viviendas y el patrimonio de los refugiados y las personas desplazadas, los cuales hacen parte del bloque de constitucionalidad (ONU, 2005).

Teniendo como base los procesos de tutela iniciados por las víctimas de desplazamiento forzado a comienzos del siglo XXI, razonados y resueltos a partir de las normas internacionales que se configuran en el bloque de constitucionalidad, es con la resolución de una demanda de inconstitucionalidad mediante la sentencia C-715 de 2012 que la Corte Constitucional, basada en los fines esenciales del Estado Social, en los convenios y tratados internacionales, en los principios establecidos por la ONU en la Resolución 60/147 de 2005, y el numeral $1^{\circ}$ del artículo 63 de la Convención Americana sobre Derechos Humanos, compila y resume las consideraciones fundamentadas en el desarrollo jurisprudencial, y reconoce como derecho fundamental la Reparación Integral de las víctimas de delitos en general, de graves violaciones de los derechos humanos y del desplazamiento forzado en especial. En este sentido señala que la reparación integral debe ser adecuada, efectiva, rápida, justa, suficiente, y proporcional a la gravedad de las violaciones y a la entidad del daño sufrido, de tal manera que en la mayor posibilidad se garantice la restitutio in integrum, esto es, devolver a las víctimas al estado que tenían antes del hecho que produjo el daño. En consecuencia, la reparación integral no se puede limitar a una sola medida pecuniaria representada en sumas económicas para indemnizar o compensar los perjuicios sufridos, además se debe reparar tanto los daños materiales como inmateriales, para lo cual es necesario tener en cuenta medidas de rehabilitación, satisfacción, restitución y garantías de no repetición, tal como lo ha establecido la Corte Interamericana de Derechos Humanos (Corte Constitucional, Sentencia C-715, 2012).

Es por lo anterior que la Corte Constitucional colombiana al otorgar el carácter de derecho fundamental a la reparación, ha fijado parámetros y estándares que guardan total coherencia con la jurisprudencia de la Corte Interamericana de Derechos Humanos, dentro de los cuales se pueden enunciar los siguientes: i) asegurar la reparación integral del daño causado a la víctima de violaciones de derechos humanos; ii) cumplir las obligaciones respecto a garantizar el derecho a la reparación integral conforme al derecho internacional en todos sus aspectos: alcance, naturaleza, modalidades y la determinación de los benefi- 
ciarios, aspectos que no pueden ser desconocidos y deben ser respetados por los Estados obligados; iii) adoptar dentro de la reparación integral medidas determinadas no solo por la justicia distributiva sino también por la justicia restaurativa, en cuanto se trata de la dignificación y restauración plena del goce efectivo de los derechos fundamentales de las víctimas; iv) aplicar de manera preferente, como garantía de los derechos fundamentales la restitución plena (restitutio in integrum), la cual pretende el restablecimiento de la víctima a la situación anterior al hecho que produjo la violación. De no ser alcanzable el restablecimiento, asegurar otras medidas compensatorias que lo acerquen a esa situación en la mayor medida posible; v) incorporar a la reparación integral otras medidas diferentes a la pecuniaria, como la restitución, la rehabilitación, la satisfacción y garantías de no repetición tanto en la dimensión individual como colectiva; vi) la reparación integral incorpora también el derecho a conocer la verdad y a que se haga justicia; y vii) la asistencia social y la ayuda humanitaria son independientes de la reparación integral señalada, toda vez que difieren en su naturaleza, carácter y finalidad (Sentencia C-715, 2012).

Sin duda, el derecho fundamental de la reparación integral ha sido desarrollado por la jurisprudencia de la Corte Constitucional, tanto en asuntos donde se resuelve la constitucionalidad de diversas normas como en la revisión de acciones de tutela, dentro de las que se encuentran: la Sentencia C-753 de 201315, Sentencia SU 254 de 2013, Sentencia T-1078 de 2012, Sentencia T-083 de 201716, Sentencia C-344 de 201717, Sentencia T-393 de 201818 y la Sentencia T-211 de $2019^{19}$, entre otras, en las que la acción de tutela no solo representa un meca-

15 Que indicó que el derecho a la reparación de las víctimas es fundamental y no puede ser limitado, negado o desconocido por razones de sostenibilidad fiscal (Corte Constitucional, Sentencia C-753, 2013).

16 En esta reitera la Corte constitucional que la reparación integral es una obligación del Estado, cuya finalidad es devolver a la víctima al estado en el que se encontraba con anterioridad al hecho que originó tal condición (Sentencia T-083, 2017).

17 En estala Corte Constitucional estimó que: “En razón del carácter evolutivo y cambiante de las categorías de perjuicios, teniendo en cuenta su creación netamente jurisprudencial, la interpretación conforme a la Constitución implica entender que la mención que realiza dicha norma es meramente indicativa y no excluye que el juez, en aras de la tutela efectiva del principio de dignidad humana, ordene la reparación integral de los perjuicios que se encuentren debidamente probados, a la luz de las categorías reconocidas jurisprudencialmente en su momento (Sentencia C-344, 2017).

18 Aquí el Tribunal de lo Constitucionalseñala que "El derecho a la reparación al igual que la verdad y la justicia, es uno de los derechos específicos de los que son titulares las víctimas de graves violaciones de derechos humanos " (Sentencia T-393, 2018).

19 "La Sala encuentra que las víctimas de violencia sexual requieren de la reparación integral, y de la protección, acompañamiento y acceso efectivo a la justicia por parte del 
nismo para la protección de los derechos, sino que en caso de graves violaciones de derechos puede fungir como una acción reparadora fundada en la garantía del derecho fundamental a la reparación integral, contenida en instrumentos del derecho internacional; y que como mandato de optimización implica que debe asegurarse la reparación integral plena, efectiva, diferencia$\mathrm{da}$, incluso, cuando sea necesario, transformadora, con el fin de dignificar a la persona y restablecerla en sus derechos.

Conforme lo expresado por Bernal Pulido, el carácter de derecho fundamental de la reparación integral (derecho subjetivo), debe analizarse desde dos perspectivas: la primera si el derecho subjetivo se puede proteger a través de la acción de tutela, porque su vulneración genera un perjuicio irremediable, no obstante el hecho que se puedan defender por medio de este mecanismo, no le otorga del todo el carácter de fundamental al derecho subjetivo vulnerado (Bernal, 2015). La Segunda a partir de las propiedades formales y materiales para determinar el carácter de fundamental a un derecho subjetivo. Así las cosas, sobre la base de las propiedades formales un derecho subjetivo recibe tal característica, siempre y cuando se cumplan una de las siguientes cuatro premisas: a) que se encuentre incluido dentro del capítulo de derechos fundamentales de la Constitución, b) que pertenezca a la Constitución la disposición de derecho fundamental, 3) que no esté detallado dentro de la constitución ni mencionado dentro del capítulo de derechos fundamentales, pero que sea incorporado al ordenamiento jurídico por otra fuente del derecho, como por ejemplo un tratado o convención internacional, y 4) que el carácter de fundamental se lo otorgue la Corte Constitucional (Bernal, 2015).

De otra parte, Bernal Pulido, analiza las propiedades materiales, dentro de las cuales revisa en el contexto de un Estado social, el carácter de fundamental de un derecho subjetivo, a partir de los derechos morales de la persona política que son protegidos frente a la sociedad y el Estado y que se basan en la libertad como principio general del Derecho, los cuales deben entenderse como la facultad de razonar, es decir, tener sentido de justicia y capacidad de ser racional, o sea ser capaz de comprender lo bueno. Estas dos facultades se pueden constituir en la base para determinar el carácter fundamental de un derecho subjetivo. Otra dimensión sobre la que se puede hacer el análisis es a partir de la faceta democrática de la persona, es decir, ya no se basa en la libertad, sino en la autonomía del ser humano, en su capacidad y consentimiento para tomar deci-

Estado, para que la reparación supere el ámbito netamente pecuniario, y en un sentido amplio incluya no únicamente la condena a los responsables, sino también el reconocimiento social del dolor y sufrimiento de las mujeres víctimas de violencia sexual, como también el repudio de lo ocurrido..." (Sentencia T-211, 2019). 
siones, luego en este caso un derecho subjetivo representa un derecho fundamental cuando protege la capacidad de discernir. Sobre la dimensión del Estado Social de garantizar a los ciudadanos las necesidades esenciales, el individuo ya no alude a la libertad ni a la autonomía sino a la solidaridad para que la sociedad o el Estado satisfagan las necesidades básicas que solo no puede satisfacer.

En el caso que ocupa este estudio, la reparación integral reviste dichas propiedades porque al realizar el análisis para determinar el carácter fundamental, se configuran varias propiedades formales y materiales mencionadas: i) la obligación adquirida por el Estado Colombiano de respetar, proteger y garantizar los derechos humanos contenidos en los tratados y convenciones internacionales, obligación que a través del bloque de constitucionalidad se ha incorporado al derecho interno, luego aun no estableciéndose el derecho de reparación integral en la constitución política de Colombia de 1991, como derecho fundamental, se ha establecido en el derecho interno a través del bloque de constitucionalidad; ii) la Corte Constitucional ha declarado mediante su jurisprudencia la reparación integral como derecho fundamental; iii) puede protegerse a través de la acción de tutela; (iv) en un Estado constitucional y social, deben primar los intereses liberales y democráticos del individuo y por ende deben protegerse y garantizarse sus necesidades.

Ante este escenario de la reparación integral planteado por la Corte Constitucional y analizado bajo los estudios de Bernal Pulido, fluye una posición crítica por parte de Henao, quien considera que lo que se ha denominado en Colombia derecho fundamental o "principio de la reparación integral", es un concepto que se ha deformado, que está en crisis, que conlleva a una mera ilusión porque se trata de un principio que no tiene valor constitucional, que es de libre regulación legislativa, limitado en su radio de acción porque no abarca los daños inmateriales y se fundamenta sobre la noción de equidad por parte de los jueces, lo que según él relativiza su aplicación, además arguye que en materia de graves violaciones a derechos humanos por los daños de masa, se limita a reparaciones simbólicas, razones estas en las que considera que la interpretación y aplicación de la reparación integral como principio aún es discutible (Henao, 2007).

A pesar de las consideraciones de Henao, la Corte Constitucional y el Consejo de Estado, dejan ver en su jurisprudencia la concepción que desde hace más de diez años se ha dado al concepto de reparación integral como derecho fundamental y principio constitucional bajo el amparo del artículo 25 y 63.1 de la Convención Americana de Derechos Humanos. Es por esta razón que en algunos de los casos de violación de derechos humanos, ante la obligación internacional del Estado de proteger los derechos humanos de sus ciudadanos, cuando éstos son violentados o vulnerados, exigen por parte del juez, asegurar a la víctima el derecho fundamental de la reparación inte- 
gral, el cual, tomándolo como principio, prevalece ante otros derechos fundamentales, como los procesales de congruencia y de no reformatio pejus, ya que estos últimos ceden, en razón a que por la vulneración de los derechos humanos y la obligación de los Estados de protegerlos, el ordenamiento jurídico interno debe dar paso al ordenamiento internacional para asegurar el restablecimiento de la dignidad humana, propendiendo de esta manera por una reparación restaurativa y en algunas ocasiones transformadora, en la cual se ordenen diferentes medidas como la rehabilitación, restitución, satisfacción, y garantías de no repetición.

\section{El principio de reparación integral en el Consejo de Estado en Colombia}

El Consejo de Estado al igual que la Corte Constitucional ha realizado un desarrollo jurisprudencial, soportado en los convenios y tratados internacionales, en el cual denota la importancia de asegurar a las víctimas de violaciones de derechos humanos una reparación integral, basada en la dignidad humana y en la garantía de la tutela judicial efectiva. Frente al tema, ha establecido que el juez administrativo debe asumir un rol dinámico frente a las exigencias de las obligaciones internacionales de los Estados que han ratificado los tratados y convenios relacionados con la protección de los derechos humanos, esto es, debe garantizar la protección de los derechos humanos toda vez que se ha transformado en un aspecto de regulación positiva que ha desbordado los límites fijados por los Estados en la defensa de la soberanía nacional.

El Consejo de Estado en coherencia con lo establecido por la Corte Interamericana de Derechos Humanos y con la propia Corte Constitucional, también ha realizado sendos estudios en los que desarrolla el deber de proteger y asegurar que se respeten los derechos humanos, de manera que éstos no sean violados en razón de las actuaciones u omisiones de la Administración o como consecuencia del conflicto interno armado. Igualmente, ha establecido con base en los principios redactados por Naciones Unidas, que las víctimas de violaciones de derecho humanos y derechos fundamentales deben tener derecho al acceso a la justicia, a conocer la verdad y a recibir reparación por los daños causados a raíz de estas violaciones.

Así las cosas, teniendo en cuenta que la Corte Constitucional acorde con los principios y estándares internacionales ha otorgado el carácter de derecho fundamental a la reparación integral, el Consejo de Estado ha hecho lo propio para incorporar dentro de sus decisiones la asegurabilidad de este derecho fundamental como garantía en los casos que ha resuelto en razón de los procesos que obedecen a la acción de reparación directa. Muestra de ello es la sentencia del 16 de agosto de 2007, en la que se resolvió una acción de 
reparación directa donde se reclamaron los perjuicios causados por miembros del Ejército Nacional, en una operación militar que dejó lesionado el señor José Alarcón quien sufrió como consecuencia del disparo una incapacidad permanente del $100 \%$. Allí con fundamento en las obligaciones internacionales del Estado, estableció la reparación del daño sufrido incluyendo obligaciones de hacer que se sumaron a la tradicional medida pecuniaria a cargo de las entidades demandadas. Dichas obligaciones hoy pueden equipararse a las contenidas en la Resolución 60/147 de 2005 y que se denominan: rehabilitación, restitución, satisfacción y garantías de no repetición. En este caso, el Consejo de Estado consideró que no puede determinarse la reparación simplemente con una medida pecuniaria o compensación económica, sino que era necesario que se adoptaran medidas que permitieran que la víctima efectivamente quedara indemne después del padecimiento del daño, para lo cual propuso que la víctima tenía derecho a conocer la verdad de lo sucedido, a recuperar la confianza en las entidades del Estado y tener la certeza de que los hechos que causaron el daño no vuelvan a repetirse. Ante la imposibilidad de que el señor Alarcón volviera a realizar actividades que hicieran agradable su existencia se ordenó una reparación consistente en lo que hoy se conoce como una medida de "rehabilitación", que sin mencionarla como tal, la establece como una obligación a cargo de la entidad demandada dentro de la reparación del daño emergente, la cual conlleva a asegurar a la víctima la atención hospitalaria y médico quirúrgica que requiera, así como los medicamentos que necesite para recuperar la salud, cuando quiera que las secuelas de la lesión sufrida lo demanden, incluyendo además, gastos de transporte que requiera, así como la silla de ruedas que necesitara (Consejo de Estado, Sentencia 30114, 2007).

Pero es a partir de la sentencia de octubre 19 de 2007 cuando el Consejo de Estado realiza una valoración del principio de reparación integral a partir del Sistema Interamericano de Derechos Humanos, en especial de las decisiones de la Corte Interamericana de Derechos Humanos y de los principios establecidos por la ONU, para lo cual hace un estudio descriptivo y argumentativo de lo que significa la obligación internacional del Estado de asegurar a las víctimas de violaciones de derechos humanos la aplicación de las normas que integran el bloque de constitucionalidad (Sentencia 291273A, 2007).

Igualmente, en sentencia que se puede considerar como hito del 20 de febrero de 2008 con ponencia del Magistrado Enrique Gil Botero, el Consejo de Estado resuelve un caso de violación de derechos humanos de los hermanos Carmona Castañeda, quienes fueron privados de su libertad, encontrándose bajo custodia de la policía Nacional y posteriormente asesinados. Allí el alto tribunal inserta en su decisión la obligación de asegurar el derecho fundamental de la reparación integral en virtud de los principios y directrices internacionales en 
el sentido de garantizar a las víctimas de estas violaciones recursos eficaces y la reparación integral de los perjuicios sufridos. En este caso no solo se limita a ordenar la tradicional medida indemnizatoria, sino que aplica el principio de reparación integral ordenando medidas no pecuniarias como: satisfacción que implica la obligación de presentar públicamente en ceremonia oficial excusas a los familiares por los hechos ocurridos en cuanto a la desaparición forzada y muerte de los hermanos Carmona; se ordena la publicación de la parte resolutiva de la sentencia en un lugar visible de la policía en Tuluá; se ordenan medidas de garantía de no repetición a cargo de la policía nacional en cuanto a diseñar e implementar un programa de capacitación de promoción y respeto por los derechos humanos de las personas mediante eventos académicos y educativos en la ciudad (Sentencia 16996, 2008).

A partir de estos pronunciamientos del Consejo de Estado se marcan las pautas en la jurisdicción contencioso administrativa para asegurar la aplicación del principio de reparación integral en favor de las víctimas de violaciones graves y manifiestas de los derechos humanos y del derecho internacional humanitario, e incluso extendiendo estas medidas en favor de aquellas víctimas de violaciones de derechos fundamentales. De esta manera se configura en adelante la aplicación del principio de reparación integral fundado en escenarios de justicia restaurativa en las que se incorporan medidas que si bien no contienen valor económico, propenden por el restablecimiento y la dignificación de las víctimas. Al respecto, ha expresado esta alta corporación que el principio de reparación integral debe asegurarse bajo la premisa de que es un derecho fundamental. Por ello, el juez de lo contencioso administrativo debe procurar su materialización, asegurando a la víctima el restablecimiento y dignificación, incorporando las medidas de reparación del estándar internacional y propendiendo por el resarcimiento del daño, con el fin de que la persona que lo haya padecido vuelva al menos, a un punto cercano al que tenía antes de la ocurrencia del mismo, para lo cual debe asegurar en la mayor medida de lo posible la restitución a su statu quo.

Como consecuencia, para el alto tribunal, el principio de reparación integral debe ser interpretado y aplicado cuando el daño causado provenga de la violación a un derecho humano o incluso cuando se refiera a la lesión de un bien o interés jurídico que no se relaciona con el sistema de derechos humanos (DDHH). Y en el caso de vulneración de derechos humanos la indemnización económica con miras al cubrimiento de un determinado perjuicio o detrimento no es suficiente, por lo que deben asegurarse otras medidas de reparación, de las contenidas en la Resolución AR60/147 de 2005 proferida por la ONU (2005).

Para asumir tal posición, el Consejo de Estado ha tenido en cuenta las decisiones de la Corte Interamericana en los casos contra el Estado Colombiano, tales 
como: "Masacre Pueblo Bello vs. Colombia" (CIDH, 2006)20; "Masacre de Ituango vs Colombia" (CIDH, 2006) 21; "Masacre La Rochela vs Colombia" (CIDH, 2007) ${ }^{22}$; Valle Jaramillo y otros vs. Colombia (CIDH, 2008) ${ }^{23}$ y "Masacre Santo Domingo vs. Colombia" (CIDH, 2012) ${ }^{24}$. En estas se puede desta-

20 Aquí la CIDH protegió Derechos a la vida, a la integridad personal, la libertad personal, a las garantías judiciales y a la protección judicial para acceder a la justicia, todos relacionados con la obligación general de respetar y garantizar los derechos establecidos en el artículo 1.1 de la Convención Americana de los Derechos humanos, en los hechos ocurridos el 14 de enero de 1990 en el municipio de pueblo Bello (Antioquia), relacionados con una incursión paramilitar en la que secuestraron y asesinaron a un grupo de personas (CIDH, 2006).

21 Con esta sentencia se protegieron: Derechos a la vida, a la libertad personal, a la propiedad privada, a no ser constreñidos a ejecutar trabajo forzoso u obligatorio ..., a la circulación y residencia, a la integridad personal, a la protección de la honra y de la dignidad, a las garantías judiciales y a la protección judicial para acceder a la justicia, además de los derechos del niño,todos relacionados con la obligación general de respetar y garantizar los derechos establecida en el artículo 1.1 de la Convención Americana de los Derechos humanos, el Convenio de la OIT, el manual de las Naciones unidas, los principios rectores de los desplazamientos internos de la ONU. Violaciones causadasen los hechos ocurridos en Municipio de Ituango, específicamente en el sitio llamado La granja el 11 de junio de 1996 y los ocurridos entre el 22 de octubre y el 12 de noviembre en el sitio conocido como el Aro, en los que un grupo de paramilitares torturaron, esclavizaron y asesinaron a un grupo de personas, además de robarles sus cabezas de ganados y de incendiar sus casas (CIDH, 2006).

22 En esta sentencia se reconoció que existió violación de los derechos a la vida, a la integridad personal, a la libertad personal, a las garantías judiciales y a la protección judicial para acceder a la justicia, relacionados con la obligación general de respetar y garantizar los derechos establecida en el artículo 1.1 de la Convención Americana de los Derechos humanos,como consecuencia de los hechos ocurridos el 18 de enero de 1989 en el bajo Simacota (Santander) que se refieren a la ejecución extrajudicial de 12 funcionarios de la administración de justicia y las lesiones a 3 más, que cumplían funciones en razón de un proceso judicial. violaciones ejecutadaspor parte de un grupo paramilitar llamado "Los masetos" (CIDH, 2007).

23 La Corte considera que un Estado tiene la obligación de adoptar todas las medidas necesarias y razonables para garantizar el derecho a la vida, libertad personal e integridad personal de aquellos defensores y defensoras que denuncien violaciones de derechos humanos y que se encuentren en una situación de especial vulnerabilidad como lo es el conflicto armado interno colombiano, siempre y cuando el Estado tenga conocimiento de un riesgo real e inmediato en contra de éstos y toda vez que existan posibilidades razonables de prevenir o evitar ese riesgo (CIDH, 2008).

24 La Corte Interamericana reconoce la violación de los derechos a la vida de adultos y niños, a la integridad personal de adultos y niños y familiares de las víctimas, a la propiedad privada y al derecho de circulación y residencia, relacionados con la obligación general de respetar y garantizar los derechos, establecida en el artículo 1.1 de la Convención Americana de los Derechos humanos, los cuales fueron vulnerados en los actos perpetrados el 13 de diciembre de 1998 a las 10:02 am en los que la tripulación de un helicóptero de la fuerza Aérea Colombiana (FAC) lanzó un dispositivo clúster, compuesto por seis bombas de fragmentación, sobre la zona urbana de la vereda de Santo Domingo, lo que resultó en 17 civiles muertos, entre ellos cuatro niños y dos niñas, y 27 civiles heridos, entre ellos cinco niñas y cuatro niños (CIDH, 2012). 
car además de la aplicación efectiva del principio de reparación integral, varios puntos importantes que se resumen de esta manera: a) el reconocimiento de responsabilidad expresado por el Estado, en algunos casos total, en otros parcial; b) la solicitud de perdón a las víctimas en las audiencias públicas que se desarrollaron en virtud del procedimiento establecido por la Corte; c) los acuerdos parciales de reparaciones y los acuerdos conciliatorios realizados en la jurisdicción interna; d) la formulación de propuestas de reparación a las víctimas. Aspectos que han sido incorporados por el Consejo de Estado en decisiones respecto de condenas relacionadas con la protección y garantía de los derechos humanos.

Lo anterior evidencia que las medidas de reparación establecidas por la Organización de las Naciones unidas y aplicadas por la CIDH, se han incorporado en la legislación interna y en la jurisprudencia de la Sección Tercera del Consejo de Estado (Guerra y Clavijo, 2015). Sin embargo, es importante tener claro que hasta el año 2008 las medidas de reparación aplicadas en los casos de reparación directa no contenían el carácter de derecho fundamental pese a que la Corte Constitucional ya lo había determinado como tal, la reparación era meramente pecuniaria, consistían en establecer un valor económico para indemnizar el daño material y compensar el daño inmaterial. Fue a partir de las sentencias proferidas por la Corte Interamericana de Derechos Humanos contra Colombia en las que se ordenaron medidas ejemplarizantes, de la Resolución AR/60/147 de 2005 de la ONU (2005), y de las obligaciones internacionales contenidas en diferentes tratados y convenios internacionales de protección de los derechos humanos, suscritos y ratificados por Colombia.

Es cierto que, en la actualidad tanto la Corte Constitucional como el Consejo de Estado y la misma Corte Suprema de Justicia, propenden por asegurar a las víctimas una reparación integral "adecuada, diferenciadora, transformadora y efectiva”" (Congreso de la República, Ley 1448, 2011) que restaure la dignidad y que se encuentra perfectamente relacionada con la verdad y la justicia.

\section{El daño inmaterial a ser reparado bajo el principio de reparación inte- gral, en la jurisprudencia del Consejo de Estado}

Aunque para algunos autores como Solarte Rodríguez (2009) y Sandoval Garrido (2013) la reparación integral debe reconocerse solamente para los perjuicios materiales o patrimoniales, toda vez que con ella se alcanzaría la verdadera reparación in natura, en el sentido que son bienes o intereses susceptibles de valoración económica, mientras que los extrapatrimoniales no lo son. Para Henao (Henao, 2007) en Colombia son reparables conforme a la clasificación o tipología del daño, el daño material y el daño inmaterial, tanto de carácter individual como colectivo. Luego en este sentido y conforme 
se ha señalado en la normativa internacional e interna y en la jurisprudencia ya mencionada, el principio de reparación integral debe asegurarse a las víctimas para reparar de manera plena el daño que se haya causado a sus derechos, bienes e intereses bien sean materiales o inmateriales, asegurando con ésta la indemnidad y su dignificación.

En la legislación civil se establecen las categorías de daños materiales, dentro de las cuales se definen: i) el daño emergente, cuando ha existido pérdida de patrimonio, erogación, salida de dinero para recomponerse a la situación sufrida por el daño y ii) el lucro cesante cuando se frustra una ganancia o ingreso esperado. Frente a los daños inmateriales, estos han evolucionado en los últimos 25 años, reconociendo diferentes tipos de daño inmaterial, los cuales se resumen así: i) el daño moral; ii) el daño a la salud y, iii) el daño especial referido a daño a un bien, derecho o interés legítimo constitucional o convencionalmente tutelado, que no esté comprendido dentro del concepto de daño corporal o afectación a la integridad psicofísica. Esto evidencia que han surgido diferentes daños inmateriales autónomos, independientes al tradicional daño moral, conocido como sentimientos de tristeza, angustia, temor, desazón, depresión y en general, todos aquellos sentimientos que impliquen la desestabilización de la esfera íntima emocional de la persona.

$\mathrm{Al}$ respecto, el Consejo de Estado consideró necesario sistematizar la reparación del perjuicio inmaterial en Colombia para determinar cuáles daños inmateriales son resarcibles. En razón de ello el consejero Enrique Gil Botero en sentencia del año 2011, elaboró un estudio sobre las diferentes categorías de daños inmateriales que deben establecerse con categoría autónoma, para ello consideró necesario analizar:

i) si se indemniza el daño en sí mismo o si por el contrario se reparan las consecuencias exteriores de ese daño; ii) cuáles son los bienes, derechos o intereses legítimos que tienen cabida en el plano de la responsabilidad y, por lo tanto, ostentan el carácter de indemnizables, y iii) si el daño derivado de lesiones psicofísicas es posible resarcirlo a través de criterios objetivos y que contengan estándares que garanticen el principio de igualdad, pues frente a una misma lesión debería declararse una idéntica o similar reparación (Consejo de Estado, Sentencia 38222, 2011).

En relación con el daño moral, ha señalado el Consejo de Estado: "Cuando se hace referencia al daño moral, se alude al generado en «el plano psíquico interno del individuo, reflejado en los dolores o padecimientos sufridos a consecuencia de la lesión a un bien" (Sentencia 19836, 2018). Este daño tiene existencia autónoma y se configura una vez satisfechos los criterios generales del daño: que sea particular, determinado o determinable, cierto, no eventual y que tenga 
relación con un bien jurídicamente tutelado. En efecto, este alto tribunal estableció frente al mismo, al menos cuatro características que permiten su identificación y definición: que sea cierto y persona ${ }^{25}$, la compensación que se otorga por este concepto es de carácter simbólico, pues tutela bienes jurídicos imposibles de cuantificar en una suma de dinero porque carece de naturaleza económica, la compensación por pretium doloris busca aliviar, más no resarcir, los padecimientos producidos ${ }^{26} ; y$, finalmente, se ha señalado que esta tipología de perjuicios requiere prueba de su existencia, no así de su cuantificación, último aspecto para el cual el juez puede acudir a su prudente arbitrio (arbitrium judicium) para cuantificar su magnitud para alcanzar su compensación ${ }^{27}$.

Por su parte, el daño fisiológico se perfiló en una decisión del Tribunal Administrativo de Antioquia en 1992 y posteriormente fue reconocido por el Consejo de Estado en la sentencia del Mayo 6 de 1993 complementándolo a la categoría de daño fisiológico o a la vida de relación refiriéndose a la pérdida de posibilidades de gozar actividades vitales que, aunque no producen rendimiento patrimonial, hacen agradable la existencia. No obstante, a partir de esta sentencia hasta el 19 de julio de 2000 se ordenó reparar el daño autónomo denominado "perjuicio fisiológico" a la víctima directa del daño ya que para su reconocimiento se requería que la víctima padeciera una lesión física y que como consecuencia de esta sufriera una afectación funcional. Fue a partir de la sentencia del 19 de julio de 2000, en la que se realizó un análisis exhaustivo de lo que es el daño fisiológico y el daño a la vida de relación, sobre lo que se concluyó que éstos no se pueden tomar como términos sinónimos, y se determinó darle categoría autónoma al perjuicio denominado "daño a la vida de relación", sobre el que se amplió el espectro para su reparación, en el sentido de que éste no es sufrido solo por la víctima por una lesión corporal sino que puede provenir de otros hechos que alteren la vida del ser humano con su exterior, con su entorno, incluso señala que un daño moral dada su gravedad modifique el comportamiento social de la víctima, o una pérdida económica que sea de gran magnitud que afecte profundamente la vida familiar y social de la víctima (Sentencia 11842, 2000). Para el Consejo de Estado y la Corte Suprema de Justicia era claro establecer que el daño a la vida de relación puede ser padecido por la víctima directa de la lesión física, pero, además de ella, lo pueden sufrir otras personas que le sean cercanas, a quienes también se les debe asegurar la reparación integral.

25 Al respecto puede consultarse: (Consejo de Estado, Sentencia 30273, 2014; Sentencia 27082, 2013; Sentencia 22390, 2012).

26 Sobre este punto consultar: (Consejo de Estado, Sentencia 1598-16, 2017).

27 Puede verse al respecto: (Consejo de Estado, Sentencia 36115, 2017; Sentencia 14769, 2016; Sentencia 23343, 2012; Sentencia 21859, 2012; Sentencia 20106, 2012). 
En la sentencia del 14 de septiembre de 2011 la Sección Tercera del Consejo de Estado estableció una nueva categoría de daño inmaterial al cual le dio plena autonomía, razón por la que desplaza por completo las otras categorías de daños inmateriales diferentes al daño moral, es decir, deja sin contenido y significado el daño a la vida de relación y la alteración a las condiciones de existencia y surge el "daño a la salud" -se reconoce como proveniente de una afectación a la integridad psicofísica-, que ha permitido solucionar o aliviar la discusión, toda vez que reduce a una categoría los ámbitos físico, psicológico, sexual, etc., de tal forma que siempre que el daño consista en una lesión a la salud, será procedente establecer el grado de afectación del derecho constitucional y fundamental (artículo 49 C.P.) para determinar una reparación por ese aspecto, sin que sea procedente el reconocimiento de otro tipo de daños (Sentencia 19031, 2011) y (Sentencia 38222, 2011).

Solo pasaron dos años para que en la sentencia de unificación de Septiembre 25 de 2013 del Consejo de Estado (Sentencia 36460, 2013), se abriera aún más el abanico de los daños inmateriales, incorporando una categoría autónoma: el daño denominado "daño a bienes o derechos constitucional o convencionalmente protegidos", aclarando que sólo son reparables cuando los hechos dan cuenta de la violación de garantías constitucionales fundamentales o convencionales, referidas específicamente a la violación de derechos humanos (Buen nombre, al derecho al trabajo o el derecho a la educación).

Conforme a lo expuesto, las formas de daño inmaterial que acorde a la jurisprudencia del Consejo de Estado pueden ser reparados de forma integral son: El daño moral, los daños a bienes constitucionales y convencionales y el daño a la salud (perjuicio fisiológico o biológico) derivado de una lesión corporal o psicofísica. Categorías autónomas del daño inmaterial o extrapatrimonial que permiten al funcionario judicial, contemplar como reparación integral distintas formas no pecuniarias de los estándares internacionales, que aseguren en la mayor medida de lo posible el restablecimiento digno de las víctimas y la aplicación del principio de indemnidad como complemento del principio de reparación integral.

\section{CONCLUSIONES}

La reparación integral es hoy un elemento fundamental en la responsabilidad civil y del Estado, la misma ha sido vista como derecho fundamental y principio constitucional por los altos tribunales en Colombia. Esta circunstancia implica nuevos desafíos para los funcionarios judiciales, quienes basados en la humanización de la justicia y la protección internacional de los derechos de los ciudadanos, deben tener claridad respecto de los daños que realmente deben 
ser reparados de manera integral, conforme a los principios establecidos en el orden interno y tomando en cuenta los estándares internacionales. La reparación integral, es vista así como un principio constitucional, que busca volver a la víctima al statu quo que gozaba antes de sufrir el daño causado por la violación de sus derechos. Lo que implica que se debe asegurar en la medida de lo posible en cualquier escenario, sea de justicia retributiva, justicia restaurativa o justicia transicional, la indemnidad y la dignificación de la víctima, en donde se le aseguren las diversas dimensiones que encierra el principio de reparación integral, que guarde coherencia con el grado o magnitud de los daños sufridos y que debe ordenarse bajo el amparo de los lineamientos legales, constitucionales y convencionales.

En los diversos pronunciamientos frente al derecho fundamental de la reparación integral emitidos por la Corte Constitucional y del Consejo de Estado en Colombia, se observa la incidencia que de este principio contenido en las normas del Derecho Internacional de los Derechos Humanos y del Derecho Internacional Humanitario se refleja en el derecho interno colombiano. Estos tribunales han incorporado medidas de justicia restaurativa fundadas en la posición imperativa de los derechos humanos, basados en el bloque de constitucionalidad. Con ello, se evidencia una cultura hacia la globalización del derecho y una tendencia de incorporación en el ordenamiento jurídico interno y en la jurisprudencia nacional de las orientaciones normativas internacionales, que deben garantizar la aplicación del principio de reparación integral no solo a las víctimas de violaciones sistemáticas de los derechos humanos y del derecho internacional humanitario, sino también a las víctimas de violaciones de derechos fundamentales y a las víctimas de cualquier daño antijurídico sufrido.

No obstante, después analizar varios aspectos expuestos en el desarrollo jurisprudencial y doctrinal, es dable concluir que el principio de reparación integral no se satisface solo con sumas pecuniarias, ni tampoco se dirige exclusivamente al restablecimiento de los intereses materiales o patrimoniales. Para su configuración plena, en el ordenamiento jurídico colombiano, requiere de otras medidas con el objetivo de propiciar el máximo nivel de restauración digna en la persona de la víctima tanto de sus bienes materiales como inmateriales. En ese orden de ideas, la reparación integral debe entenderse como el derecho prevalente de la víctima a obtener las condiciones para la transformación y restauración de su condición afectada por el hecho vulnerador, derecho que se expresa en diversas formas, entre ellas las medidas de reparación como indemnización, rehabilitación, restitución, satisfacción y garantía de no repetición, para lograr una reparación integral y equitativa dentro de un Estado social de derecho.

Igualmente debe exponerse con claridad que si bien la reparación integral se concibe como un principio que debe asegurarse y aplicarse en la mejor medi- 
da posible, este no puede concebirse como omnisciente y absoluto, pues los derechos fundamentales en veces son limitados por razones de interés general o de respeto de otros derechos. De allí que existan aspectos que delimitan su aplicación, limites que pueden resumirse de la siguiente manera: i) cada víctima o grupo de víctimas está obligado a demostrar los elementos sobre los cuales debe orientarse la estimación de las medidas de reparación de los perjuicios, conforme a sus características particulares, especificas y de contexto que permitan determinar el alcance de la reparación de los perjuicios sufridos; ii) la víctima debe demostrar la existencia de una relación causal entre el daño y el hecho, la acción u omisión ejecutada por un agente, al que le sea imputable el deber de reparar; iii) la reparación integral debe corresponderse con la magnitud de daño, no debe convertirse ni concebirse como una fuente de enriquecimiento ni de empobrecimiento de la víctima, razón por la que su finalidad obedece a criterios objetivos que aseguren el restablecimiento de la víctima a su statu quo, no debe extralimitarse ni establecer criterios sancionadores.

Por lo tanto y conforme a todo lo expresado, en Colombia, el juez cuenta con los instrumentos necesarios para la realización de una verdadera justicia material, ya que independientemente del origen del daño o la lesión del interés o del derecho, debe asegurar que, en todos los casos, la persona tenga la garantía de que la reparación del perjuicio será integral, y fundamentada en criterios de justicia.

\section{REFERENCIAS}

Asamblea Nacional Constituyente (1991). Constitucion Política de Colombia. Bogotá D.C., Colombia: Gaceta Constitucional No. 116 de 20 de julio de 1991. Disponible en: http://www.secretariasenado.gov.co/senado/basedoc/constitucion_ politica_1991.html

Bernal Pardo, F. (2017). Reparación integral diferenciada: niños, niñas y adolescentes huérfanos víctimas del conflicto armado colombiano (2011-2016). Tesis de maestria. Bogotá D.C., Colombia: Univerisdad del Rosario. Disponible en: http:/ / repository.urosario. edu.co/handle/10336/17941

Brewer Carías, A. y Santofimio, J. O. (2013). Control de Convencionalidad y responsabilidad del Estado. Bogotá D.C.: Universidad Externado de Colombia.

Corte Interamericana de Derechos Humanos (CIDH) (2006). Caso Masacre Pueblo Bello vs. Colombia. Sentencia de 31 de enero. Disponible en: http:/ / www.corteidh.or.cr/ docs/casos/articulos/seriec_140_esp.pdf 
Corte Interamericana de Derechos Humanos (CIDH) (2006). Caso Masacre de Ituango vs. Colombia. Sentencia de 1 de julio. Disponible en: http:/ / www.corteidh.or.cr/ docs/casos/articulos/seriec_148_esp.pdf

Corte Interamericana de Derechos Humanos (CIDH) (2007). Caso Masacre La Rochela vs. Colombia. Sentencia de 11 de mayo. (Fondo, Reparaciones y Costas). Disponible en: http://www.corteidh.or.cr/docs/casos/articulos/seriec_163_esp.pdf

Corte Interamericana de Derechos Humanos (CIDH) (2008). Caso Valle Jaramillo y otros vs. Colombia. Sentencia de 27 de noviembre. (Fondo, Reparaciones y Costas). Disponible en: http://www.corteidh.or.cr/docs/casos/articulos/seriec_192_esp.pdf

Corte Interamericana de Derechos Humanos (CIDH) (2012). Caso Masacre de Santo Domingo vs. Colombia. Sentencia de 30 de noviembre. (Excepciones preliminares, fondo y reparaciones). Disponible en: http:/ / www.corteidh.or.cr/docs/casos/ articulos/seriec_259_esp.pdf

Código Civil. (1804). Paris, Francia. Disponible en: https:/ / www.legifrance.gouv.fr/ content/download/1966/13751/.../Code_41.pdf

Comisión Internacional de 1 a Cruz Roja (1907). Convención relativa a las leyes y costumbres de la guerra terrestre. Conferencias de La Haya. La Haya, Países Bajos. Disponible en: https:/ / www.icrc.org/es/doc/resources/documents/misc/treaty-1907hague-convention-4-5tdm34.htm

Congreso de los Estados Unidos de Colombia. Ley 84 de 1873. Código Civil de los Estados Unidos de Colombia. Bogotá D.C., Colombia: Diario Oficial No. 2.867 de 31 de mayo de 1873. Disponible en: http:/ / www.secretariasenado.gov.co/senado/ basedoc/codigo_civil.html

Congreso de la República de Colombia. Ley 446 de 1998, «Por la cual se adoptan como legislación permanente algunas normas del Decreto 2651 de 1991, se modifican algunas del Código de Procedimiento Civil, se derogan otras de la Ley 23 de 1991 y del Decreto 2279 de 1989». Bogotá D.C., Colombia: Diario Oficial No. 43.335, de 8 de julio de 1998. Disponible en: https://www.oas.org/dil/esp/Ley_446_de_ 1998_Colombia.pdf

Congreso de la República de Colombia. Ley 468 de 1998. C, «Por medio de la cual se aprueba el Acuerdo sobre asistencia a la niñez entre la República de Colombia y la República de Chile". Bogotá D.C., Colombia: Diario Oficial año CXXXIV. No. 43360 del 11 de agosto de 1998. Disponible en: http://www.suin-juriscol.gov.co/view Document.asp?id=1832944

Congreso de la República de Colombia. Ley 975 de 2005. «Por la cual se dictan disposiciones para la reincorporación de miembros de grupos armados organizados al 
margen de la ley, que contribuyan de manera efectiva a la consecución de la paz nacional y se dictan otras disposiciones para acuerdos humanitarios». Bogotá D.C., Colombia: Diario Oficial No. 45.980 de 25 de julio de 2005. Disponible en: https://www.fiscalia.gov.co/colombia/wp-content/uploads/2013/04/Ley-975del-25-de-julio-de-2005-concordada-con-decretos-y-sentencias-de-constitucio nalidad.pdf

Congreso de la República de Colombia. Ley 1448 de 2011, «Por la cual se dictan medidas de atención, asistencia y reparación integral a las víctimas del conflicto armado interno y se dictan otras disposiciones». Bogotá D.C., Colombia: Diario Oficial No. 48.096 de 10 de junio de 2011. Disponible en: https://www. unidadvictimas.gov.co/sites/default/ files/documentosbiblioteca/ley-1448-de2011.pdf

Consejo de Estado de Colombia. Sala de lo Contencioso Administrativo. Sección Tercera (2000). Sentencia 11842 del 19 de julio de 2000. Radicado No. 253075-CE-SEC3EXP2000-N11842-11842. C.P. Alier Eduardo Hernández Enriquez.

Consejo de Estado de Colombia. Sala de lo Contencioso Administrativo. Sección Tercera (2006). Sentencia 13168 del 4 de diciembre de 2006. Radicado No. 13.168. C.P. Mauricio Fajardo Gómez.

Consejo de Estado de Colombia. Sección Tercera (2007). Sentencia 30114 del 16 de septiembre de 2007. Radicado No. 41001-23-31-000-1993-07585-01. C.P. Ramiro Saavedra Becerra.

Consejo de Estado de Colombia. Sala de lo Contencioso Administrativo. Sección Tercera. (2007). Sentencia 291273A del 19 de octubre de 2007. Radicado No. 05001-23-31000-1998-02290-01. C.P. Enrique Gil Botero.

Consejo de Estado de Colombia. Sala de lo Contencioso Administrativo. Sección Tercera (2008). Sentencia 16996 del 20 de febrero de 2008. Radicado No. 76001-23-25000-1996-04058-01(16996). C.P. Enrique Gil Botero.

Consejo de Estado de Colombia. Sala de lo Contencioso Administrativo. Sección Tercera (2011). Sentencia 19031 del 14 de septiembre de 2011. Radicado No. 200907105001-23-25-000-1994-00020-01-19031. C.P. Enrique Gil Botero.

Consejo de Estado de Colombia. Sección Tercera (2011). Sentencia 38222 del 14 de septiembre de 2011. Radicado No. 38222. C.P. Enrique Gil Botero.

Consejo de Estado de Colombia. Sala de lo Contencioso Administrativo. Sección Tercera. Subsección C. (2013). Sentencia 36460 del 25 de septiembre de 2013. Radicado No. 2015792-05001-23-31-000-2001-00799-01-36460. C.P. Enrique Gil Botero. 
Consejo de Estado. Sala de lo Contencioso Administrativo. Sección Tercera. Subsección C. (2014). Sentencia 31583 del 12 de febrero de 2014. Radicado No. 2073042-6800123-15-000-1998-01736-01-31583. C.P. Jaime Orlando Santofimio Gamboa.

Consejo de Estado de Colombia. Sala de lo Contencioso Administrativo. Sección Tercera. Subsección A. (2014). Sentencia 35930 del 29 de mayo de 2014. Radicado No. 2077139-68001-23-31-000-2002-02004-01-35930. C.P. Hernán Andrade Rincón.

Consejo de Estado de Colombia. Sala de lo Contencioso Administrativo. Sección Tercera. Sala Plena (2014). Sentencia 36149 del 28 de agosto de 2014. Radicado No. 2020578-68001-23-31-000-2002-02548-01-36149. C.P. Hernán Andrade Rincón (E).

Consejo de Estado de Colombia. Sala de lo Contencioso Administrativo. Sección Cuarta (2018). Sentencia 19836 del 3 de mayo de 2018. Radicado No. 2113757-08001-2331-0002010-00911-01-19836. C.P. Julio Roberto Piza Rodríguez.

Corte Constitucional de Colombia (2001). Sentencia T-327. 26 de marzo de 2001. M.P. Marco Gerardo Monroy Cabra.

Corte Constitucional de Colombia (2001). Sentencia T-1319. 7 de diciembre de 2001. M.P. Rodrigo Uprimny Yepes.

Corte Constitucional de Colombia (2002). Sentencia C-228. 3 de abril de 2002. M.P. Manuel José Cepeda Espinosa y M.P. Eduardo Montealegre Lynet.

Corte Constitucional de Colombia (2003). Sentencia C-067. 4 de febrero de 2003. M.P. Marco Gerardo Monroy Cabra.

Corte Constitucional de Colombia (2005). Sentencia T-085. 3 de febrero de 2005. M.P. Humberto Antonio Sierra Porto.

Corte Constitucional de Colombia (2006). Sentencia C-370. 18 de mayo de 2006. M.P. Manuel José Cepeda Espinosa.

Corte Constitucional de Colombia (2007). Sentencia T-821. 8 de octubre de 2007. M.P. Catalina Botero Marino.

Corte Constitucional de Colombia (2009). Sentencia T-085. 16 de febrero de 2009. M.P. Jaime Araujo Rentería.

Corte Constitucional de Colombia (2011). Sentencia T-076. 8 de febrero de 2011. M.P. Luis Ernesto Vargas Silva.

Corte Constitucional de Colombia (2011). Sentencia T-159. 10 de marzo de 2011. M.P. Humberto Antonio Sierra Porto. 
Corte Constitucional de Colombia (2012). Sentencia C-715. 13 de septiembre de 2012. M.P. Luis Ernesto Vargas Silva.

Corte Constitucional de Colombia (2012). Sentencia C-820. 18 de octubre de 2012. M.P. Mauricio Gonzáles Cuervo.

Corte Constitucional de Colombia (2012). Sentencia T-1078. 12 de diciembre de 2012. M.P. Jorge Ignacio Pretelt Chaljub.

Corte Constitucional de Colombia (2013). Sentencia SU-254. 24 de abril de 2013. M.P. Luis Ernesto Vargas Silva.

Corte Constitucional de Colombia (2013). Sentencia C-753. 30 de octubre de 2013. M.P. Mauricio Gonzáles Cuervo.

Corte Constitucional de Colombia (2017). Sentencia C-344. 24 de mayo de 2017. M.P. Alejandro Linares Cantillo.

Corte Constitucional de Colombia (2017). Sentencia T-083. 13 de febrero de 2017. M.P. Alejandro Linares Cantillo.

Corte Constitucional de Colombia (2018). Sentencia T-393. 24 de septiembre de 2018. M.P. Alberto Rojas Ríos.

Corte Constitucional de Colombia (2019). Sentencia T-211. 20 de mayo de 2019. M.P. Cristina Pardo Schlesinger.

Corte Suprema de Justicia de Colombia Sala de Casación Civil (2013). Sentencia SC199426630. 1 de noviembre de 2013. Radicado No. 08001-3103-008-1994-26630-01. M.P. Arturo Solarte Rodríguez.

Corte Suprema de Justicia de Colombia Sala de Casación Civil. (2015). Sentencia SC11575-2015. 5 de mayo de 2015. Radicado No. 11001-31-03-020-2006-00514-01. M.P. Fernando Giraldo Gutiérrez.

Cubides Cárdenas, J. A., Chacón Triana, N., y Martínez Lazcano, A. J. (2015). El control de convencionalidad (CCV): retos y pugnas. Una explicación taxonómica. 6 (11), 53-94. Disponible en: http://www.unilibrecucuta.edu.co/ojs/index.php/derecho/article/view/86/80

De Cupis, A. (1970). El daño. Teoría general de la Responsabilidad Civil. (A. Marti?nez Sarrio?n, Trad.) Barcelona: Bosch.

Escobar Gil, R. (1989). Responsabilidad contractual e la administración pública. Bogotá D.C.: Temis S.A. 
Gómez Montañez, J. A. (2014). Derecho a la reparación y la lucha contra la impunidad ante las graves violaciones a los derechos humanos. Revista Academia E Derecho, 5(8), 99-118. Disponible en: http:/ / www.unilibrecucuta.edu.co/ojs/index.php/ derecho/article/view/81/75

Guerra Moreno, D. L. (2015). Aplicación de los principios y directrices de la reparación integral del derecho internacional en el derecho interno colombiano. «Control Convencional y Constitucional». En Aspectos especiales de la responsabilidad civil y del Estado. Una visión moderna (pp. 181-217). Bogotá D.C.: Grupo Editorial Ibáñez.

Guerra Moreno, D. L. (2015). Tendencias del lucro cesante en el régimen de responsabilidad extracontractual del Estado en el derecho colombiano, a partir de la Constitución de 1991. Revista Academia E Derecho, 6(10), 157-184. Disponible en: http:/ /www.unilibrecucuta.edu.co/ojs/index.php/derecho/article/view/4/5

Guerra Moreno, D. L., y Clavijo Cáceres, D. (2015). Reparación integral: la justicia restaurativa como tendencia de la reparación directa en Colombia. Bogotá D.C.: Grupo Editorial Ibañez.

Guerra Moreno, D. L., y Quintero Pérez, M. I. (2015). Responsabilidad del Estado por la función jurisdiccional. «El error judicial y la privación injusta de la libertad». En Aspectos especiales de la responsabilidad civil y del Estado (pp. 131-148). Bogotá D.C.: Grupo Editorial Ibáñez.

Guzmán Rodríguez, D. E. (2009). Reparar en Colombia: Los dilemas en contextos de conflicto, pobreza y exclusión. Bogotá D.C.: De Justicia. Disponible en: https:// www.dejusticia.org/wp-content/uploads/2017/04/fi_name_recurso_164.pdf

Hart, H. L. (2016). El concepto de responsabilidad. En A. Fernández Fernández, Homenaje al maestro José Barroso Figueroa por el Colegio de Profesores de Derecho Civil (pp. 95-110). México D.F.: UNAM.

Henao Pérez, J. C. (2007). El daño. Bogotá D.C.: Universidad Externado de Colombia.

Henao Pérez, J. C. (2007). Le dommage: analyse à partir de la responsabilité civile extracontractuelle de l'Etat en droit colombien et endroit français. Tesis doctorado. Bogotá D.C., Colombia. Disponible en: https:/ / bdigital.uexternado.edu.co/handle/ $001 / 277$

Henao Pérez, J. C. (2015). Las formas de reparación en la responsabilidad del Estado: hacia su unificación sustancial en todas las acciones contra el Estado. Revista de Derecho Privado (28), 277-366. Disponible en: https:/ / revistas.uexternado.edu.co/ index.php/derpri/article/view/4133

Kelsen, H. (2010). Teoría general del Derecho y del Estado. México D.F.: UNAM. 
Mazeaud, H., Mazeaud, L., Tunc, A., Capitant, H., y Alcalá Zamora y Castillo, L. (1997). Tratado teórico práctico de la responsabilidad civil delictual y contractual (Vol. I). Buenos Aires: Ediciones Jurídicas Europa-América.

Organización de Estados Americanos (OEA) (1969). Convención Americana sobre Derechos Humanos. San José, Costa Rica. Disponible en: https:/ / www.oas.org/dil/esp/ tratados_b-32_convencion_americana_sobre_derechos_humanos.htm

Organización de los Estados Americanos (0EA) (1985). Convención para prevenir y sancionar la tortura. Cartagena de Indias, Colombia. Disponible en: https:// www.oas.org/juridico/spanish/firmas/a-51.html

Organización de los Estados Americanos (OEA) (1988). Protocolo de San Salvador. Protocolo Adicional a la Convención Americana sobre Derechos Humanos en materia de Derechos Económicos, Sociales y Culturales. San Salvador, El Salvador. Disponible en: https://www.oas.org/juridico/spanish/tratados/a-52.html

Organización de Estados Americanos (OEA) (1994). Convención Interamericana para prevenir, sancionar y erradicar la violencia contra la mujer. Convención de Belem Do Para. Brasil. Disponible en: https://www.oas.org/juridico/spanish/tratados/a-61.html

Organización de las Naciones Unidas (ONU) (26 de junio de 1945). Carta de las Naciones Unidas. Conferencia de las Naciones Unidas sobre Organización Internacional. San Francisco, Estado Unidos. Disponible en: https://www.un.org/es/ charter-united-nations/

Organización de las Naciones Unidas. Asamblea General (1948). Declaración Universal de Derechos Humanos. Resolución 217 A (III). Paris, Francia. Disponible en:e https:/ /www.ohchr.org/EN/UDHR/Documents/UDHR_Translations/spn.pdf

Organización de las Naciones Unidas (ONU) (1949). V Convenio de Ginebra. 12 de agosto de 1949. Conferencia Diplomática para Elaborar Convenios Internacionales destinados a proteger a las víctimas de la guerra. Relativo a la protección debida a las personas civiles en tiempo de guerra. Ginebra, Suiza. Disponible en: https:// www.icrc.org/es/doc/resources/documents/treaty/treaty-gc-4-5tdkyk.htm

Organización de las Naciones Unidas. Asamblea General (ONU) (1966). Pacto Internacional de Derechos Civiles y Políticos. Resolución 2200 A (XXI). New York, Estados Unidos. Disponible en: https:/ / www.ohchr.org/SP/ProfessionalInterest/Pages/ CCPR.aspx

Organización de las Naciones Unidas (ONU) (1977). Protocolo I adicional a los Convenios de Ginebra. Relativo a la protección de las víctimas de los conflictos armados internacionales. Disponible en: https://www.icrc.org/es/document/protocolo-i- 
adicional-convenios-ginebra-1949-proteccion-victimas-conflictos-armados-internacionales-1977

Organización de las Naciones Unidas. Asamblea General (ONU) (1984). Convención contra la Tortura y Otros Tratos o Penas Crueles, Inhumanos o Degradantes. Resolución 39/46. Disponible en: https://www.ohchr.org/sp/professionalinterest/pages/ cat.aspx

Organización de las Naciones Unidas. Asamblea General (ONU ( 1989). Convención sobre los derechos del niño. Resolución 44/25. Disponible en: https:/ / www.un.org/ es/events/childrenday/pdf/derechos.pdf

Organización de las Naciones Unidas (1998). Estatuto de Roma. Conferencia Diplomática de plenipotenciarios de las Naciones Unidas sobre el establecimiento de una Corte Penal Internacional. Roma, Italia. Disponible en: https:/ /www.un.org/spanish/law/ icc/statute/spanish/rome_statute(s).pdf

Organización de las Naciones Unidas. Oficina de Coordinación de Asuntos Humanitarios (ONU) (1998). Principios Rectores de los desplazamientos internos. (11 de febrero de 1998). Disponible en: https:/ / www.acnur.org/fileadmin/Documentos/BDL/ 2001/0022.pdf

Organización de las Naciones Unidas. Consejo Económico y Social (ONU) (2005). Principios sobre la restitución de las viviendas y el patrimonio de los refugiados y las personas desplazadas. (17-28 de junio de 2005). Comisión de Derechos Humanos. Subcomisión dePromoción y Protección. Pinheiro, Brasil. Disponible en: https:/ / www.acnur.org/fileadmin/Documentos/Publicaciones/2008/6325.pdf

Organización de las Naciones Unidas. Asamblea General (ONU) (2005). Resolución 60/147. Principios y directrices básicos sobre el derecho de las víctimas de violaciones manifiestas de las normas internacionales de derechos humanos y de violaciones graves del derecho internacional humanitario a interponer recursos y obtener reparaciones. Disponible en: https://www.ohchr.org/SP/ProfessionalInterest/Pages/Remedy AndReparation.aspx

Organización Internacional del Trabajo. (OIT) (1989). Convenio No. 169. Sobre pueblos indigenas y tribales. Ginebra, Suiza. Disponible en: https:/ / www.ilo.org/wcmsp5/ groups/public/ - americas/ - ro-lima/documents/publication/wcms_345065. pdf

Pabón Giraldo, L. D. (2015). Incidencia de criterios jurisprudenciales desarollados por algunos tribunales internacionales en las reformas procesales y práctica judicial colombiana. En El precedente judicial y el ejercicio del derecho ante las altas cortes (pp.358-391). Medellín: Sello editorial Universidad de Medellín. 
Ramírez Carvajal, D. M. (2019). La prueba del hecho fragmentado-un análisis a partir de la responsabilidad Médica. En Constitución y los hechos en el proceso. Editorial Ibañez.

Sánchez Vallejo, J. (2015). Entre la recepción y la omisión de una obligación internacional: el control de convencionalidad en el Consejo de Estado. Revista Academia \& Derecho, 6(11), 183-226. Disponible en: http://www.unilibrecucuta.edu.co/ojs/ index.php/derecho/article/view/90/84

Sandoval Garrido, D. A. (2013). Reparación Integral y responsabilidad civil: el concepto de reparación integral y su vigencia en los daños extrapatrimoniales a la persona como garantía de los derechos de las víctimas. Revista de Derecho Privado(25), 235-271. Disponible en: https:// revistas.uexternado.edu.co/index.php/ derpri/article/view/3602/3696

Solarte Rodríguez, A. (2009). El principio de reparación integral del daño en el derecho colombiano. En Tendencias de la responsabilidad civil en el siglo XXI (pp. 121157). Pontificia Universidad javeriana, Diké.

Tamayo Jaramillo, F. J. (1983). El daño civil y su reparación. Revista Facultad de Derecho y Ciencias Politicas(63), 36-70. Disponible en: https://revistas.upb.edu.co/ index.php/derecho/article/view/5868

Trad. Idelfonso, G. d. (1889). Cuerpo del Derecho Civil Romano. Barcelona: Consejo de Ciento.

Unidad de Víctimas. (26 de julio de 2019). Registro Nacional de Víctimas. Disponible en: https://www.unidadvictimas.gov.co/es/registro-unico-de-victimas-ruv/37394

Uprimny Yepes, R., y Guzman Rodríguez, D. E. (2010). En búsqueda de un concepto transformador y participativo para las reparaciones en contextos transicionales. Revista Colombiana de Derecho Internacional, 231-286. Disponible en: https:// www.dejusticia.org/wp-content/uploads/2017/04/fi_name_recurso_679.pdf

Yáñez Meza, D. A. (2016). Responsabilidad Constitucional: El juez de tutela en la reparación de daños. Bogotá D.C.: Universidad Externado de Colombia. 